\title{
Kinetic Monte Carlo Modeling of the Sulfinyl Precursor Route for Poly( $p$-phenylene vinylene) Synthesis
}

\author{
Paul H. M. Van Steenberge, ${ }^{\dagger}$ Joke Vandenbergh, ${ }^{\ddagger}$ Dagmar R. D’hooge, ${ }^{\dagger}$ Marie-Françoise Reyniers, ${ }^{*+}$ \\ Peter J. Adriaensens, ${ }^{\neq}$Laurence Lutsen, ${ }^{\S}$ Dirk J. M. Vanderzande, ${ }^{\ddagger, \S}$ and Guy B. Marin ${ }^{\dagger}$ \\ ${ }^{\dagger}$ Laboratory for Chemical Technology (LCT), Ghent University, Krijgslaan 281 (S5), B-9000 Gent, Belgium \\ ${ }^{\ddagger}$ Institute for Materials Research (IMO), Hasselt University, Universitaire Campus, Agoralaan Building D, B-3590 Diepenbeek, Belgium \\ ${ }^{\S}$ Division IMOMEC, IMEC, Universitaire Campus, Wetenschapspark 1, B-3590 Diepenbeek, Belgium
}

Supporting Information

ABSTRACT: A kinetic Monte Carlo modeling study is presented for precursor polymer formation via the sulfinyl precursor route. The premonomer, 1-(chloromethyl)-4-[(n-octylsulfinyl)methyl]benzene, is subjected to a $\mathrm{Nat} \mathrm{BuO}$ induced 1,6-elimination in $\mathrm{sBuH}$ yielding the actual $p$-quinodimethane monomer that leads, via a radical polymerization, to the precursor polymer. The kinetic Monte Carlo model is able to predict the experimental trends in yield, mass averaged molar mass and structural defect content. The effect of radical recombination and cyclization is modeled and found to be negligible.

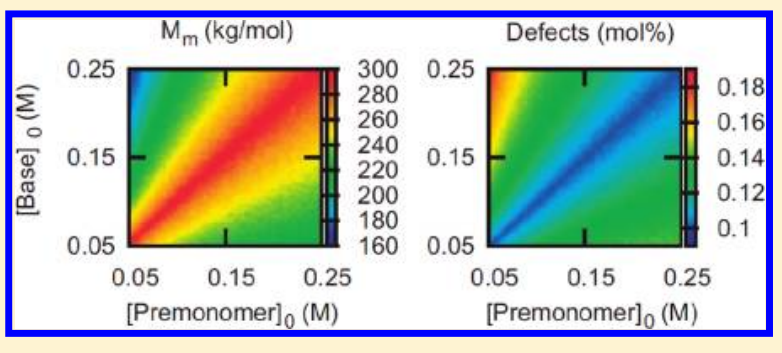
The effect of the initial base and premonomer concentration on the polymer properties is investigated. Simulation results indicate a maximum in the polymer yield and chain length for initial [base]/[premonomer] $=1$ and that the molecular properties of the precursor polymers can be varied by as much as $50 \%$ by an appropriate choice of initial [base]/[premonomer]. The kinetic Monte Carlo model is used to determine reaction conditions to achieve targeted polymer yields, chain lengths and structural defect contents.

\section{INTRODUCTION}

Since the discovery ${ }^{1}$ of the luminescence of poly $(p$-phenylene vinylene) (PPV) and the subsequent device fabrication ${ }^{2}$ of light emitting diodes (LEDs) using PPV layers, this type of conjugated polymers have drawn significant interest. PPVs are currently used in solar cells, LEDs, thin film transistors (TFT), field effect transistors (FET), chemical and biosensors, laserdyes, ${ }^{3-5}$ scintillators, ${ }^{3}$ piezoelectric and pyroelectric materials, ${ }^{6}$ photoconductors ${ }^{7}$ to switch elements, and data processors. ${ }^{6,8,9}$ The major advantages of using PPVs as the active layer in semiconductor devices are their low-cost solution processing into large surface area coatings and the possibility of designing new materials by modification of their molecular structure. The microstructure of the PPV is a key parameter for opto-electronic applications since it strongly influences the chain packing and morphology in the final polymer films. Low molar mass polymers are less suited because the produced films are fragile and less stable. ${ }^{10}$ For LED fabrication, high molar mass polymers favor the formation of lamellar structures and correspondingly higher charge mobility. ${ }^{11,12}$

PPVs can be synthesized in various ways, ${ }^{13-21}$ but most frequently a precursor route is used to obtain a soluble, high molar mass precursor polymer. As illustrated in Figure 1, various precursor routes have been developed. Common to all these precursor routes is that a $\alpha, \alpha^{\prime}$-disubstituted $p$-xylene premonomer is subjected to a base induced 1,6-elimination yielding the active $p$-quinodimethane monomer that leads to a precursor polymer via radical and/or anionic quinoid polymerization. The conjugated PPV is formed from the precursor polymer through a series of intramolecular thermally, base or, in some specific cases, acid-induced ${ }^{22}$ eliminations.

To obtain high performance materials, a pure, soluble and thermally stable precursor polymer must be obtained that undergoes a clean thermal elimination reaction toward the conjugated structure. Also, tuning of the conjugation length ${ }^{23-29}$ and control of the defect content $\mathrm{t}^{30-41}$ are key factors to obtain PPVs with the desired electroluminescence and photoluminescence properties. Control of the molar mass of the polymer and optimization of the number of critical defects in the synthesized PPVs requires a detailed knowledge of the reaction kinetics. Several studies have investigated the reaction mechanism that governs polymer formation via the various precursor routes. Although each precursor route has its own characteristics, there exists some mechanistic analogy between the various precursor routes. In particular, for the Gilch, ${ }^{42}$ the sulfinyl, and the dithiocarbamate route, a series of detailed studies performed by the groups of Rehahn ${ }^{33,34,36-39,41,43}$ and Vanderzande ${ }^{31,35,44-59}$ has revealed mechanistic similarities in precursor polymer formation. There are convincing indications ${ }^{31,44,48,50,52,55,60,61}$ that in polar

Received: July 15, 2011

Revised: October 6, 2011

Published: October 25, 2011 


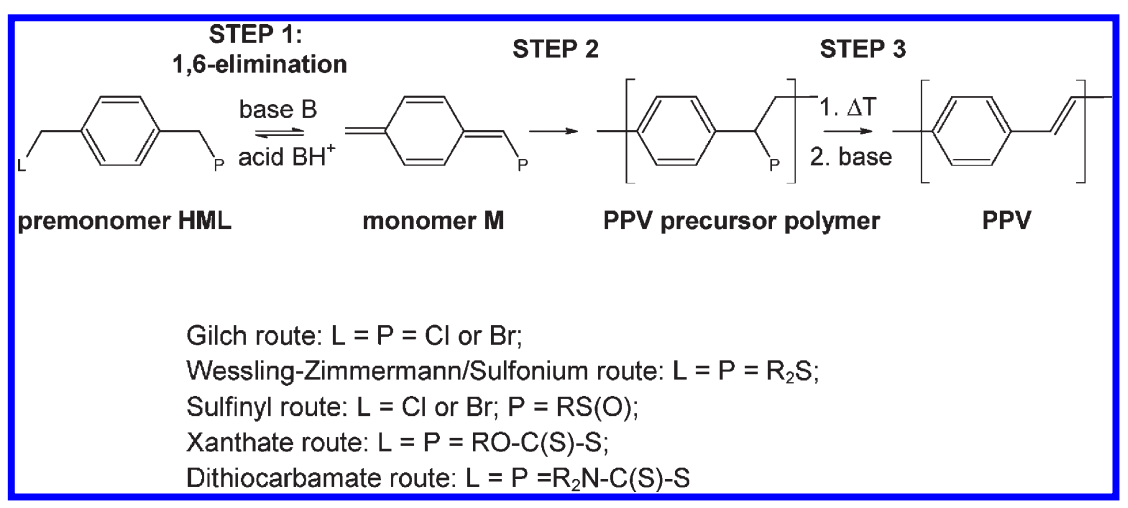

Figure 1. Precursor routes toward poly ( $p$-phenylene vinylene) (PPV) derivatives.

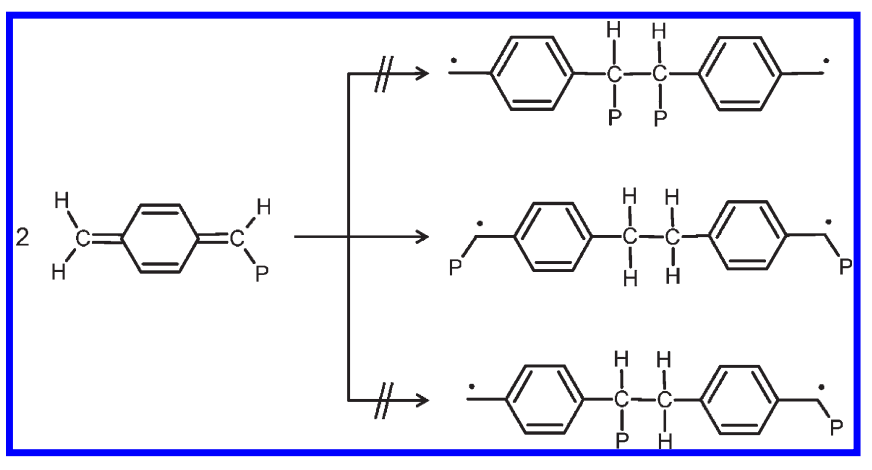

Figure 2. Initiator radicals produced by dimerization of the monomer.

aprotic solvents, radical and anionic quinoid polymerization can proceed in parallel; higher molar mass polymer is thought to originate form a radical chain mechanism while a parallel anionic polymerization mechanism produces lower molar masses leading to a precursor polymer which displays a bimodal molar mass distribution. ${ }^{31,44,48,50,52,55,60,61}$ In protic solvents, the anionic mechanism seems to be suppressed effectively and high molar mass precursor polymer is produced mainly via a free radical polymerization $33,44,46,48,50,52,53,55,60,62-64$ that is initiated by spontaneous dimerization of the active pquinodimethane monomer to dimer diradicals. Experimental and theoretical studies $33,34,36-38,49,53,60,64-68$ indicate that the preferred mode of initiation involves formation of the diradical which has both radicals located at terminal CHP groups, see Figure 2 .

Two reasons have been put forward to explain the dominance of this initiation path. First, $\mathrm{C}-\mathrm{C}$-bond formation between the two $\mathrm{CH}_{2}$ groups is least sterically hindered and, second, both radicals centers are stabilized by the presence of the polarizer $\mathrm{P}$ in the terminal CHP-group. Next to chain initiation, the diradical can undergo intramolecular radical recombination leading to the formation of [2.2] paracyclophane sideproducts. ${ }^{37-39,69}$ It has been suggested ${ }^{37-39,44,65,66,69,70}$ that radical chain propagation is not merely a conventional free radical polymerization but that a more complex binary mechanism is operative in which, next to the "conventional" 1,6-type addition to the radical chain ends, recombination of growing $\alpha, \omega$-macro-diradicals can contribute to chain growth too. In contrast to conventional free radical polymerization, recombination of two $\alpha, \omega$-macro-diradicals does not lead to a dead polymer but to another $\alpha, \omega$-macrodiradical which can grow further by addition of monomer.
As can be seen in Figure 1, the various precursor routes differ in the chemical structure of the leaving group (L) and the polarizer $(\mathrm{P})$. Precursor routes in which the polarizer and leaving group are identical, such as the Gilch, ${ }^{42}$ the WesslingZimmermann/sulfonium, ${ }^{63}$ the xanthate ${ }^{28,71,72}$ and the dithiocarbamate $^{59,31}$ routes, offer less synthetic possibilities to improve the quality of the polymer properties than the sulfinyl route which features a differentiation between the alkyl sulfinyl polarizer and the halogen (mostly $\mathrm{Cl}$ or $\mathrm{Br}$ ) leaving group. This differentiation between leaving group and polarizer in the sulfinyl route opens up synthetic possibilities unseen in any other precursor route, such as (i) improved solubility via structural variation of the alkylsulfinyl group, (ii) improved viscosity characteristics, (iii) reduction of the number of defects due to irregular chain growth, and (iv) the use of extended aromatic moieties, all of which enable the synthesis of conjugated polymers with emission wavelengths tuned by molecular structure.

The attractiveness of the sulfinyl precursor route to synthesize high performance PPVs mainly stems from the fact that the sulfinyl group is not prone to basic elimination and its thermal elimination typically requires mild heating. Combined with the excellent leaving capacity of the halogen that ensures quantitative p-quinodimethane formation, the sulfinyl route allows synthesizing pure and thermally stable precursor polymer at low temperatures (Figure 1, STEP 2). In contrast, in the Gilch route, the quinoid polymerization (Figure 1, STEP 2) is accompanied by intramolecular elimination (Figure 1, STEP 3) because the chlorine polarizer in the precursor polymer is prone to basic elimination. This typical elimination behavior of the sulfinyl group has also been exploited to obtain modified PPV derivatives with restricted conjugation length. ${ }^{73}$ Controlled oxidation of the sulfinyl precursor polymer produces a polymer that possesses both sulfinyl and sulfonyl groups. Selective elimination of the sulfinyl group is then possible because it can be eliminated at temperatures as low as $140{ }^{\circ} \mathrm{C}$, whereas elimination of the sulfonyl group requires temperatures above $400{ }^{\circ} \mathrm{C}$. A similar tuning of the conjugation length was performed for the Wessling route. ${ }^{24}$ By precisely controlling the molar fraction of the sulfonyl group, which functions as the defect restricting the conjugation length, the physical properties of the materials can be optimized.

The differentiation between leaving group and polarizer in the sulfinyl route also leads to materials with very low structural defect contents, as shown in a ${ }^{13} \mathrm{C}$ NMR study on labeled polymers: ${ }^{35}$ the measured content of defects fell below the 


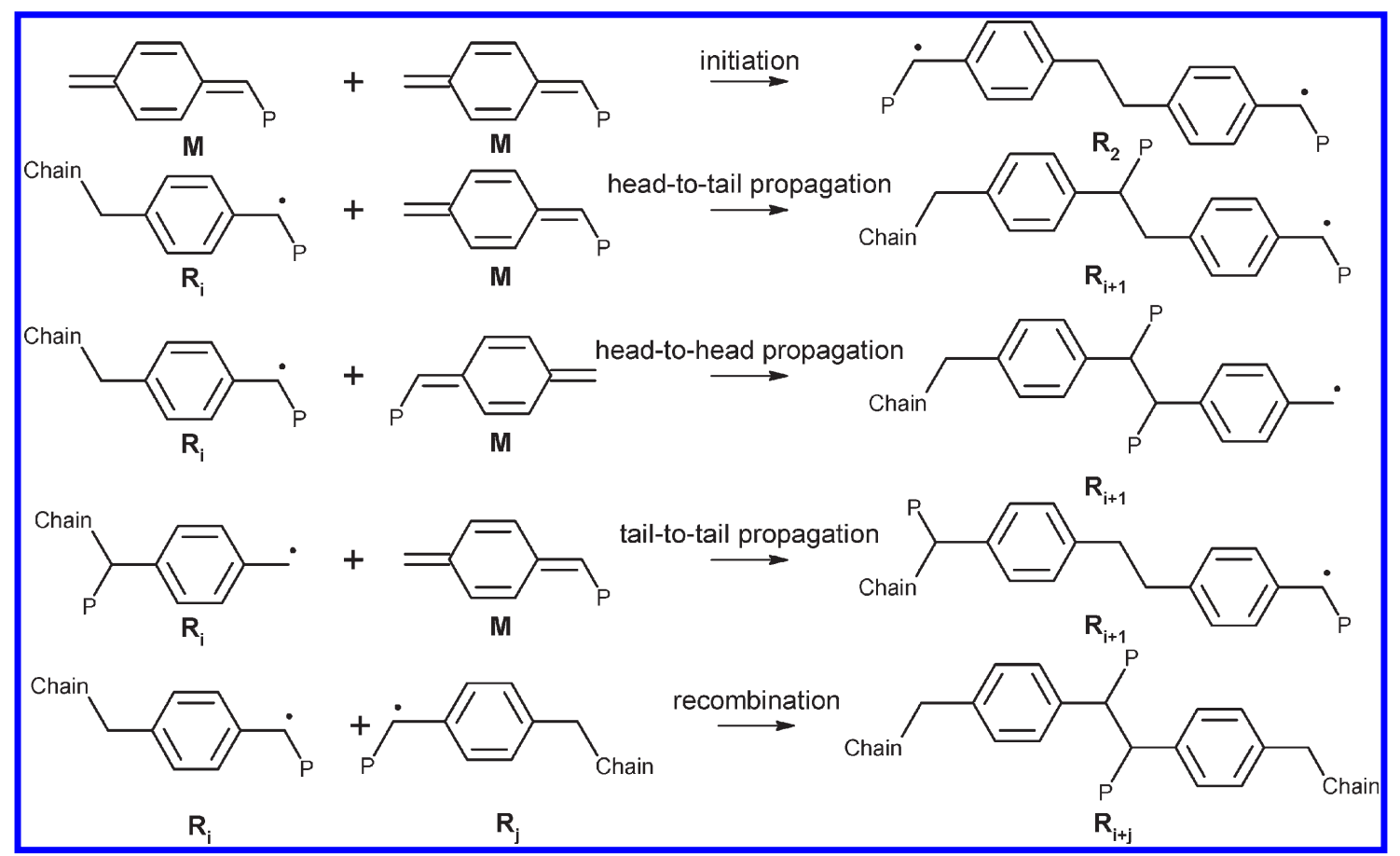

Figure 3. Structural defects resulting from initiation and recombination in precursor routes. Head-to-tail propagation does not lead to structural defects, whereas head-to-head and tail-to-tail propagation are known to be negligible in the sulfinyl route.

detection limit of $0.1 \%$. The formation of polymer chains with low amounts of defects is attributed to the dominant occurrence of head-to-tail addition during chain growth (Figure 3). Defects in the polymer chain such as $\mathrm{CH}_{2}-\mathrm{CH}_{2}$ bonds can be introduced via tail-to-tail addition while $\mathrm{CHS}(\mathrm{O}) \mathrm{R}-\mathrm{CHS}(\mathrm{O}) \mathrm{R}$ bonds can be formed via head-to-head addition and/or recombination of $\alpha, \omega$-macro-diradicals. The only defects formed during the sulfinyl polymerization are believed to be related to initiation (Figure 2 and 4 ) and recombination. In contrast to the low-defect sulfinyl polymers, the Gilch route was shown ${ }^{35}$ to produce higher amounts of structural defects, which were proposed to result from head-to-head and tail-to-tail addition and the occurrence of $\alpha, \omega$-macro-diradical recombination. According to Schwalm et al., ${ }^{38}$ the occurrence of $\alpha, \omega$-macrodiradical recombination in the Gilch route could explain the tremendously high molar masses (up to one million $\mathrm{g} / \mathrm{mol}$ ) obtained via this PPV precursor route.

Currently, the nature of the termination steps in quinoid polymerization and their influence on the polymer yield, the structural defect content and the molar mass distribution remain unclear. As mentioned above, conventional recombination of radicals does not completely terminate chain growth due to the diradical nature of the propagating species. Also, no obvious reaction path is available for chain termination by disproportionation since the absence of a $\beta$-hydrogen at the chain ends prevents $\beta$-hydrogen abstraction and double bond formation. ${ }^{37,38,65}$ Transfer to solvent or to other transfer agents is largely ineffective to limit the chain length because of the very high propagation rates. ${ }^{37,65,68,69,74}$ Concerning transfer to polymer, strong indications for the absence of transfer to polymer have been reported by Rehahn's group. ${ }^{43}$ According to Schwalm et al., ${ }^{37-39}$ this type of polymerization would therefore lead to essentially infinite chain lengths. However, in practice, termination reaction can occur due to the presence of oxygen $^{35,44,48,64,65}$ or other impurities ${ }^{35,37-39,48,65}$ in the reaction mixture or by cyclization ${ }^{68}$ of the $\alpha, \omega$-macro-diradical.

In $p$-xylylene free radical polymerization, Errede et al. found ${ }^{69}$ that termination does not occur by interaction with atmospheric oxygen and that polymerization proceeds until all monomer is consumed or the radical ends of the linear polymer chains become entrapped in the polymer chain mesh. In diluted solution, the decrease of the radical concentration displayed a second order dependence on the total radical concentration, excluding cyclization as the main termination mechanism for the larger radicals. The formation of cyclic low molar mass products was attributed to cyclization of oligomeric $\alpha, \omega$-diradicals.

Despite the immense potential of conjugated polymers, kinetic modeling studies for precursor routes toward PPV synthesis are scarce. ${ }^{51,67,75-77}$ For the Wessling route, Cho et al. ${ }^{67,76}$ have extensively studied the kinetics of monomer formation and polymerization. For the $p$-quinodimethane formation, these authors suggested a reversible E1cb mechanism, in which the deprotonation to the carbanion is reversible and the expulsion of the leaving group is the rate-determining step in the elimination reaction. A kinetic model was developed which allowed a good prediction of the polymer yield. However, no attention was given to the modeling of the molecular polymer properties such as average molar mass, defect content and chain length distribution and the occurrence of recombination and cyclization reactions was not considered. For the sulfinyl route, Puyn et al. ${ }^{77}$ reported observed rate coefficients for monomer formation from 4-[(n-butylsulfinyl)methyl]-4'-(chloromethyl)benzene with $\mathrm{Nat} \mathrm{BuO}$ in dichloromethane/ $\mathrm{N}$-monomethyl formamide and the subsequent polymerization. Recently, Hermosilla et al. ${ }^{51}$ studied the kinetics of monomer formation in the sulfinyl precursor route using stop-flow UV-vis spectroscopy and theoretical calculations. Kinetic measurements were performed for various premonomers with $\mathrm{Nat} \mathrm{BuO}$ in pseudo-first-order 


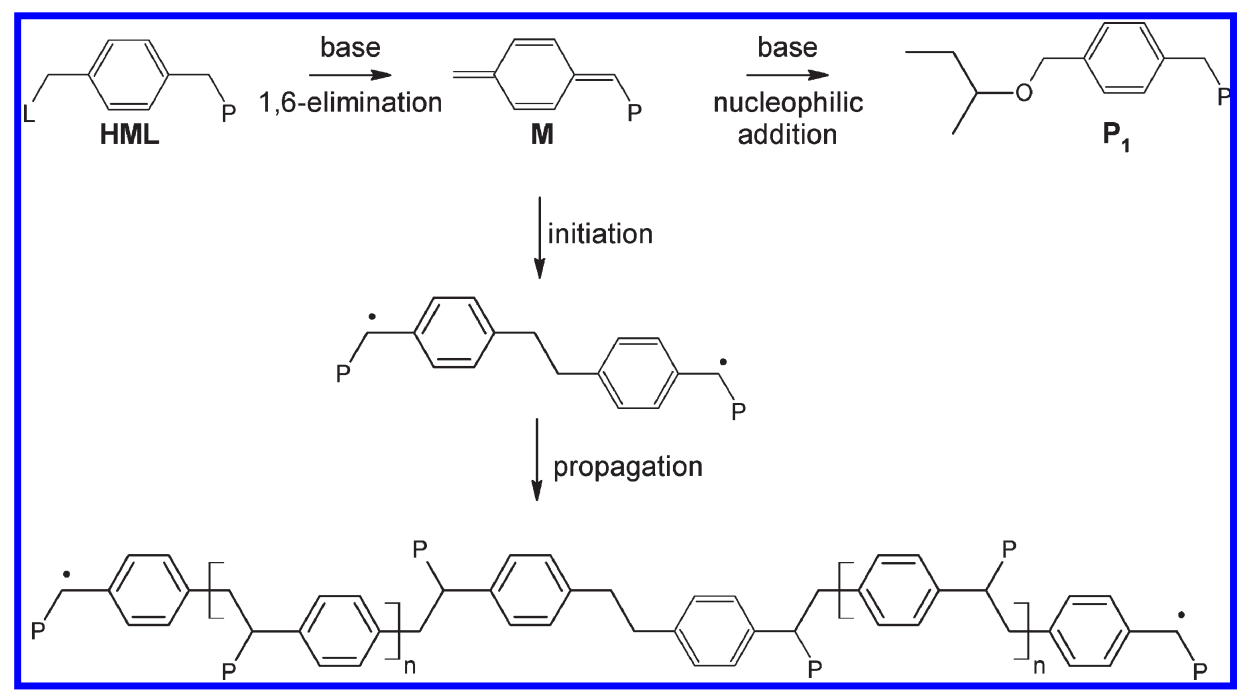

Figure 4. General reaction scheme for p-quinodimethane formation and its consumption by conjugate nucleophilic addition and polymerization via the sulfinyl route. $\mathrm{HML}$, premonomer; $\mathrm{L}$, leaving group; $\mathrm{P}$, polarizer; $\mathrm{M}$, monomer; $\mathrm{P}_{1}$, ether byproduct. Recombination and cyclization reactions are not shown.

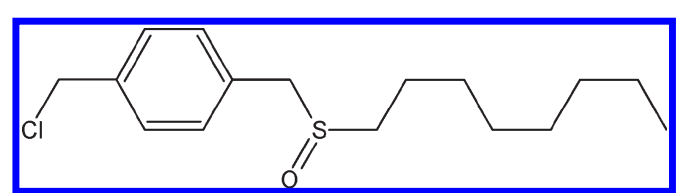

Figure 5. Structure of 1-(chloromethyl)-4-[(n-octylsulfinyl)methyl]benzene.

reaction conditions in $\mathrm{sBuOH}$. At these conditions, polymer formation is effectively suppressed while conjugated nucleophilic addition is the only monomer consuming reaction (see Figure 4). On the basis of the experimental results and the theoretical calculations, these authors proposed an E2 mechanism for the base induced 1,6-elimination. Rate coefficients were reported for the E2 elimination step only. A kinetic model for formation of the p-quinodimethane monomer and its polymerization via the sulfinyl route is still lacking.

Clearly, the availability of a kinetic model enabling to tune the reaction conditions in order to obtain optimal precursor polymer yield, structural defect content and molar mass distribution can contribute to realize the tremendous potential of the sulfinyl route to synthesize PPVs with controlled properties. In this work, a kinetic Monte Carlo model for precursor polymer formation via the sulfinyl precursor route from 1-(chloromethyl)-4-[(n-octylsulfinyl)methyl] benzene (see Figure 5) with $\mathrm{NatBuO}$ in $\mathrm{sBuOH}$ is presented.

To model monomer formation, the rate coefficients for E2 elimination and conjugate nucleophilic addition are determined from in situ stop-flow UV-vis measurements using low initial premonomer concentrations and a large excess of $\mathrm{Nat} B u \mathrm{O}$ to suppress polymerization. To model precursor polymer formation, rate coefficients for radical polymerization of the $p$-quinodimethane are obtained from data reported in literature. The kinetic Monte Carlo method is used due to calculate the entire molar mass distribution. This method is easy to implement and does not rely on assumptions such as the quasi steady state approximation for reactive species. Unlike other numerical methods, no manual fine-tuning of numerical integration parameters is necessary, due to the brute-force nature of the method.
Then, the kinetic Monte Carlo simulations are benchmarked by comparison with simulations using the PREDICI software ${ }^{78,79}$ and used to evaluate the importance of termination by recombination of all $\alpha, \omega$-macrodiradicals and cyclization of small $(i=2$, 3 , and 4) $\alpha, \omega$-diradicals. Their effect on the simulated yields and polymer properties is discussed. Finally, the kinetic Monte Carlo model is used to study the effect of the reaction conditions on the polymer yield and properties.

\section{EXPERIMENTAL PROCEDURES}

Chemicals were purchased from Aldrich or Acros and used without further purification. The synthesis procedure of 1-(chloromethyl)-4-[(noctylsulfinyl)methyl] benzene (Figure 5) has been reported elsewhere. ${ }^{80,81}$ In situ UV-vis experiments were performed using a Cary 500 UV-vis-NIR spectrophotometer equipped with a stop-flow module (Hi-Tech Limited) according to the procedure described by Hermosilla et al. ${ }^{51}$ The optic path length of the sample cell was $10 \mathrm{~mm}$. All spectroscopic and kinetic data were obtained using the "Scanning kinetics" and "Kinetics" software module supplied by Varian. Solutions of $10^{-4} \mathrm{M}$ of the premonomer 1(chloromethyl)-4-[( $n$-octylsulfinyl)methyl $]$ benzene in $\mathrm{sBuOH}$ were used while base solutions were prepared by dilution of a $0.1 \mathrm{M}$ sodium-butoxide solution in $\mathrm{sBuOH}$. All solutions were degassed with nitrogen prior to the kinetic UV-vis experiment. The temperature of the reacting solutions was maintained at $298 \mathrm{~K}$. To determine the rate coefficients related to the monomer formation, $\mathrm{NatBuO}$ was added in excess, creating pseudo-firstorder conditions.

In accordance with the observations reported by Hermosilla et al., ${ }^{51}$ no indication for polymerization was found during the kinetic runs in this work and the only products absorbing in the UV-vis spectrum are the premonomer (HML), the $p$-quinodimethane monomer $(\mathrm{M})$ and the ether byproduct $\left(\mathrm{P}_{1}\right)$. The maximum of the $\mathrm{UV}-\mathrm{vis}$ absorbance of the $p$ quinodimethane is situated around a wavelength of $313 \mathrm{~nm},{ }^{51,77}$ which is also the wavelength used in the UV-vis experiments in this study to monitor the $p$-quinodimethane. As indicated by Hermosilla et al., ${ }^{51}$ the contributions to the absorbance at $313 \mathrm{~nm}$ of the premonomer and the substitution product $\mathrm{P}_{1}$ can be neglected. The $p$-quinodimethane concentration is thus directly proportional to the total absorbance at $313 \mathrm{~nm}$.

Kinetic Monte Carlo Model. A kinetic Monte Carlo (kMC) model was developed on the basis of the stochastic simulation algorithm 


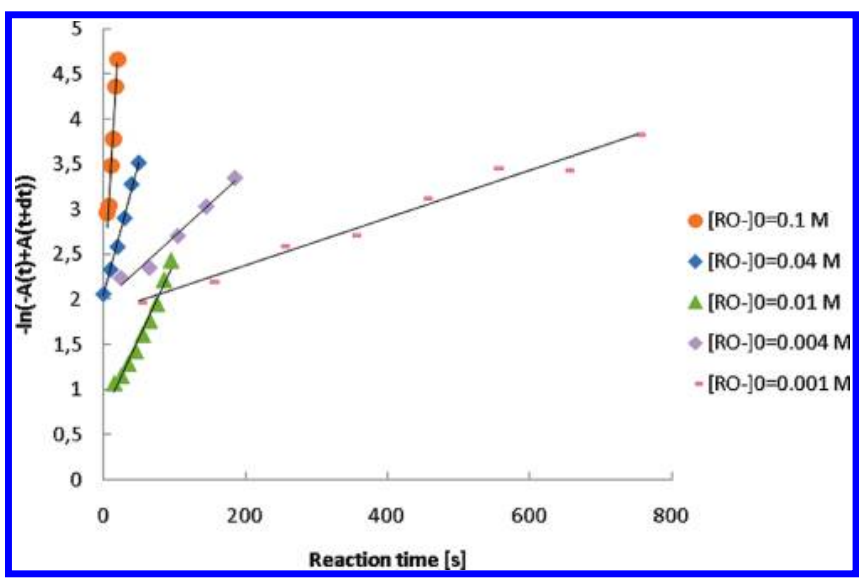

Figure 6. Plot of $-\ln (A(t+\Delta t)-A(t))$ as a function of reaction time and base concentration. Reaction conditions: $298 \mathrm{~K},[\mathrm{HML}]_{0}=10^{-4} \mathrm{M}$, $\left[\mathrm{RO}^{-}\right]_{0}=10^{-3} \mathrm{M}, 4 \times 10^{-3} \mathrm{M}, 10^{-2} \mathrm{M}, 4 \times 10^{-2} \mathrm{M}, 10^{-1} \mathrm{M}$. Symbols: experimental data from the Guggenheim method. Full line: linear regression. The slope of the straight lines is the observed rate coefficient for the 1,6-elimination as a function of the base concentration.

Table 1. Observed Rate Coefficients for Monomer Formation $^{a}$

\begin{tabular}{ccc}
{$\left[\mathrm{RO}^{-}\right]_{0}(\mathrm{M})$} & 1,6-elimination $\left(\mathrm{s}^{-1}\right)$ & nucleophilic addition $\left(\mathrm{s}^{-1}\right)$ \\
0.1 & 0.1214 & 0.0206 \\
0.04 & 0.0297 & 0.0059 \\
0.01 & 0.0172 & 0.0047 \\
0.004 & 0.0072 & $\mathrm{~N} / \mathrm{A}$ \\
0.001 & 0.0026 & $\mathrm{~N} / \mathrm{A}$ \\
${ }^{a}$ Reaction conditions: $298 \mathrm{~K},[\mathrm{HML}]_{0}=10^{-4} \mathrm{M}$, and $\left[\mathrm{RO}^{-}\right]_{0}=10^{-3}$ \\
$\mathrm{M}, 4 \times 10^{-3} \mathrm{M}, 10^{-2} \mathrm{M}, 4 \times 10^{-2} \mathrm{M}, 10^{-1} \mathrm{M}$. \\
\hline
\end{tabular}

developed by Gillespie. ${ }^{82}$ Details of this method and the reasons for its use are given in section 1 of the Supporting Information.

\section{RESULTS AND DISCUSSION}

Kinetic Modeling of Monomer Formation. In the in situ UV-vis experiments, the kinetics of monomer formation were separated from the polymerization kinetics by adding $\mathrm{Nat} B u \mathrm{O}$ in excess and creating pseudo-first-order conditions. The absorbance of the reaction mixture at $313 \mathrm{~nm}$ was measured as a function of the reaction time. The Guggenheim method ${ }^{83,84}$ was applied to extract kinetic information on the formation of the monomer by 1,6-elimination $\left(k_{\mathrm{E} 2}\right.$, see Figure 4$)$ and its disappearance to the ether byproduct, $\mathrm{P}_{1}$, by conjugate nucleophilic addition ( $k_{\mathrm{NA}}$, see Figure 4$)$. In all cases, the absorbance at $313 \mathrm{~nm}$ first increased to a maximum value and then decreased with time, indicating that the $p$-quinodimethane monomer accumulated before undergoing nucleophilic addition.

The value for the rate coefficient of the 1,6-elimination is determined from the absorbance at low reaction times, i.e. the region where the 1,6-elimination proceeds much faster than the nucleophilic addition (see Supporting Information, section 2). Figure 6 shows the plots of $-\ln \left(A_{t+\Delta t}-A_{t}\right)$ versus time for the reaction between 1-(chloromethyl)-4-[(n-octylsulfinyl)methyl] benzene and $\mathrm{NatBuO}$ in $\mathrm{sBuOH}$. For all five base concentrations, pseudo-first-order plots are obtained over multiple half-lives of the reaction. The observed

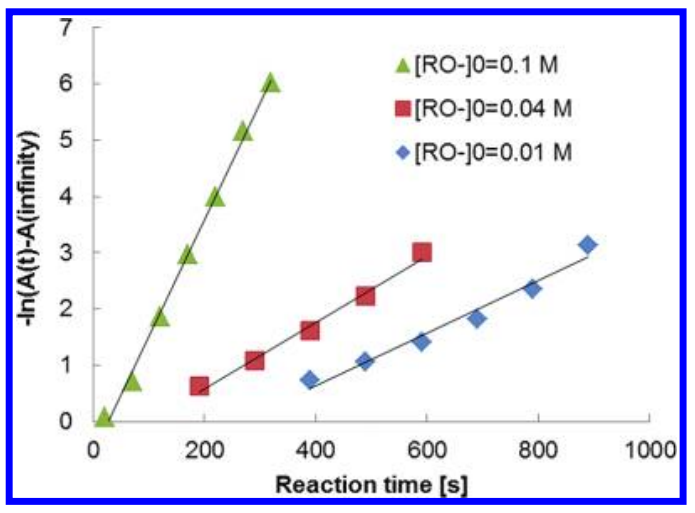

Figure 7. $-\ln (A(t)-A(\infty))$ as a function of reaction time. Reaction conditions: $298 \mathrm{~K},[\mathrm{HML}]_{0}=10^{-4} \mathrm{M},\left[\mathrm{RO}^{-}\right]_{0}=10^{-2} \mathrm{M}, 4 \times 10^{-2} \mathrm{M}$, $10^{-1}$ M. Symbols: experimental data from the Guggenheim method. Full line: linear regression. The slope of the straight lines is the observed rate coefficient for the nucleophilic addition.

rate coefficients, $k_{\mathrm{obs}}\left(\mathrm{s}^{-1}\right)$, and their corresponding $\mathrm{NatBuO}$ concentrations $(\mathrm{M})$ are presented in Table 1 . Within this concentration range, the 1,6-elimination rate clearly shows pseudo-firstorder dependence on the $\mathrm{Nat} \mathrm{BuO}$ concentration, which was also observed by Hermosilla et al. ${ }^{51}$ Linear regression (see Supporting Information, section 3 ) yields the intrinsic, bimolecular rate coefficient $k_{\mathrm{E} 2}\left(\mathrm{~s}^{-1} \mathrm{M}^{-1}\right)$ for the 1,6-elimination as $k_{\mathrm{E} 2}=1.2 \mathrm{M}^{-1} \mathrm{~s}^{-1}$ at $298 \mathrm{~K}$. Hermosilla et al. ${ }^{51}$ reported a value of $14 \mathrm{M}^{-1} \mathrm{~s}^{-1}$ at $298 \mathrm{~K}$ for $k_{\mathrm{E} 2}$. Using a similar approach as the one used in this work, Pyun et al. ${ }^{77}$ reported a value of $0.44 \mathrm{M}^{-1} \mathrm{~s}^{-1}$ for the rate coefficient of the 1,6-elimination of 1-(chloromethyl)-4-[(n-octylsulfinyl)methyl]benzene with $\mathrm{NatBuO}$ in $\mathrm{CH}_{2} \mathrm{Cl}_{2} / \mathrm{MMF}(4 / 6)$ at $298 \mathrm{~K}$. The value determined in this work is situated between Pyun's and Hermosilla's values and gives reasonable agreement with experimental data in combination with literature values for the polymerization kinetics (vide infra).

The Guggenheim method can also be used to determine the value for the rate coefficient of the nucleophilic addition from the absorbance at high reaction times, i.e., the region where the nucleophilic addition is proceeding much faster than the 1,6elimination. Figure 7 shows the plots of $-\ln \left(A_{t}-A_{\infty}\right)$ for the three highest base concentrations $0.01 \mathrm{M}, 0.04$ and $0.1 \mathrm{M}$.

Only the pseudo-first-order rate coefficient for the highest base concentration is used for the calculation of the value for the rate coefficient of the nucleophilic addition, the reasoning being that potential polymerization is suppressed most effectively when the nucleophilic addition is proceeding fastest. From the slope obtained for the $\ln \left(A_{t}-A_{\infty}\right)$ plot for $[\mathrm{NatBuO}]_{0}=0.1 \mathrm{M}$, it is clear that the observed rate coefficient for the nucleophilic addition is $0.02 \mathrm{~s}^{-1}$. As mentioned above, the only reactant consuming the $p$-quinodimethane is the base in the nucleophilic addition. Therefore, by definition, $k_{\mathrm{obs}}=$ $k_{\mathrm{NA}}[\mathrm{NatBuO}]_{0}$. Solving for $k_{\mathrm{NA}}$ yields $k_{\mathrm{NA}}=0.2 \mathrm{M}^{-1} \mathrm{~s}^{-1}$. Using all three observed rate coefficients results in the same value of $k_{\mathrm{NA}}=$ $0.2 \mathrm{M}^{-1} \mathrm{~s}^{-1}$ (see Supporting Information section 3). A value for the rate coefficient for the nucleophilic addition of the base was not reported in the kinetic studies by Hermosilla et al. ${ }^{51}$ or Pyun et al. ${ }^{77}$ The final value of $k_{\mathrm{NA}}=0.2 \mathrm{M}^{-1} \mathrm{~s}^{-1}$ for the rate coefficient for the nucleophilic addition is used as input in the kinetic Monte Carlo modeling, together with the earlier determined value of $k_{\mathrm{E} 2}=$ $1.2 \mathrm{M}^{-1} \mathrm{~s}^{-1}$ for the rate coefficient for the 1,6-elimination.

To relate the absorbance of the $p$-quinodimethane monomer at $313 \mathrm{~nm}$ to its concentration, its extinction coefficient, $\varepsilon$, in 
$\mathrm{sBuOH}$ is required. However, this extinction coefficient cannot be measured directly because the monomer is not stable and, hence, it must be determined by matching ${ }^{76}$ the simulated $p$ quinodimethane concentration with the normalized UV-vis absorbance. Therefore, the extinction coefficient was fitted to the UV-vis data using the kinetic parameters for $k_{\mathrm{E} 2}$ and $k_{\mathrm{NA}}$ determined above until a best fit between the experimental and calculated data was obtained. A value of $\varepsilon=1.48 \times 10^{4}$ $\mathrm{M}^{-1} \mathrm{~cm}^{-1}$ was obtained. The approximated value for the extinction coefficient determined ${ }^{76}$ by Cho et al. amounts to $2.9 \times 10^{4} \mathrm{M}^{-1} \mathrm{~cm}^{-1}$ for sulfonium substituted $p$-quinodimethanes in water. For more stable compounds ${ }^{76}$ values of $\varepsilon$ are in the range $(1.65-6.36) \times 10^{4} \mathrm{M}^{-1} \mathrm{~cm}^{-1}$. Also reported ${ }^{80}$ in the literature is the extinction coefficient for the repeating unit in a conjugated PPV chain, i.e., $2 \times 10^{4} \mathrm{M}^{-1} \mathrm{~cm}^{-1}$. This must be considered an upper limit for the monomer itself because the polymer chain possesses more $\pi$-conjugation. Finally, Denton et al. report ${ }^{85} 1.2 \times 10^{4} \mathrm{M}^{-1} \mathrm{~cm}^{-1}$ for sulfonium substituted p-quinodimethanes in water, which differs more than a factor 2 from Cho's value. Denton et al. also refer to a value of $1.27 \times 10^{4}$ $\mathrm{M}^{-1} \mathrm{~cm}^{-1}$ for the stable tetracyanobenzoquinodimethane in $\mathrm{MeOH}^{85}$

Figure 8 illustrates the agreement between simulated and experimental UV-vis absorbance for representative initial base concentrations $[\mathrm{Na} t \mathrm{BuO}]_{0}=0.1 \mathrm{M}$ and $0.01 \mathrm{M}$. Clearly, the kinetic model succeeds in describing the exponential regions of the $p$-quinodimethane intermediate reasonably well.

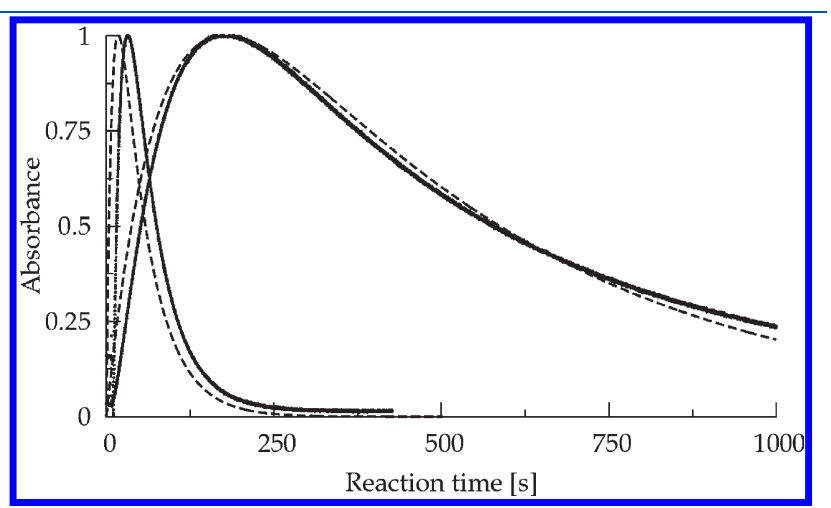

Figure 8. Normalized UV-vis absorbance at $313 \mathrm{~nm}$ as a function of reaction time. Reaction conditions: $298 \mathrm{~K},[\mathrm{HML}]_{0}=10^{-4} \mathrm{M},\left[\mathrm{RO}^{-}\right]_{0}$ $=10^{-1}, 10^{-2} \mathrm{M}$. Full line: experimental data. Dotted line: simulated data. Fitted extinction coefficient $=14820 \mathrm{M}^{-1} \mathrm{~cm}^{-1}$.
Kinetic Modeling of Precursor Polymer Formation. Radical p-Quinodimethane Polymerization. Precursor polymer formation via the sulfinyl route from 1-(chloromethyl)-4-[( $n$ octylsulfinyl)methyl] benzene with $\mathrm{Nat} \mathrm{BuO}$ in $\mathrm{sBuOH}$ has been reported by van Breemen et al. ${ }^{55}$ Table 2 summarizes the reported polymerization conditions, product yields and precursor polymer properties. Using a premonomer concentration $[\mathrm{HML}]_{0}=0.1 \mathrm{M}$ and sodium tert-butoxide concentrations of $[\mathrm{Nat} B u O]_{0}=0.05,0.13$, and $0.2 \mathrm{M}$ in sBuOH at $308 \mathrm{~K}$, a mixture of the reactant premonomer, ether byproduct and polymer results in each case. Precursor polymer yields range from $42 \%$ to $88 \%$ and display a maximum as a function of the initial base concentration. The mass averaged molar masses range from $236-249 \mathrm{~kg} / \mathrm{mol}$ and are only slightly influenced by the initial base concentration while the initiator and recombination defect content remained very low in all cases. Clearly, the occurrence of recombination between $\alpha, \omega$-macro-diradicals contributes only marginally to chain growth in the sulfinyl route. Therefore, in a first step, recombination between $\alpha, \omega$-macro-diradicals is not considered in the kinetic scheme used to model precursor polymerization in the sulfinyl route. Also, since no experimental data is available on the formation of oligomeric cyclic species produced by intramolecular cyclization of small $\alpha, \omega$-macrodiradicals, this reaction was not considered in the kinetic model in a first step.

Values for the rate coefficients for the radical initiation and propagation reactions (see Table 3), based on data available in literature, were used to describe the experimental data of Van Breemen et al. presented in Table 2. Beach ${ }^{86}$ described chemical vapor deposition of $p$-quinodimethanes and subsequent polymerization using rate coefficients derived from the work of

Table 3. Values for the Rate Coefficients at $308 \mathrm{~K}$ for the Reactions Shown in Figure 4

$\begin{array}{ll} & k\left(\mathrm{M}^{-1} \mathrm{~s}^{-1}\right) \\ \text { 1,6-elimination (E2) } & \\ \mathrm{RO}^{-}+\mathrm{HML} \rightarrow \mathrm{M}+\mathrm{ROH}+\mathrm{L}^{-} & 1.2 \\ \text { nucleophilic addition (NA) } & \\ \mathrm{RO}^{-}+\mathrm{M} \rightarrow \mathrm{P}_{1} & 2 \times 10^{-1} \\ \text { radical initiation (ini) } & 3 \times 10^{-3} \\ \mathrm{M}+\mathrm{M} \rightarrow \mathrm{R}_{\text {ini }} & \\ \text { radical propagation }(\mathrm{p}) & 1.34 \times 10^{3} \\ \mathrm{R}_{\mathrm{i}}+\mathrm{M} \rightarrow \mathrm{R}_{\mathrm{i}+1} & \end{array}$

Table 2. Simulated Polymer Properties as a Function of the Base Concentration and Reaction System at $t=3600 \mathrm{~s}^{d}$

\begin{tabular}{|c|c|c|c|c|c|c|c|}
\hline & \multicolumn{2}{|c|}{$\left[\mathrm{RO}^{-}\right]_{0}=0.05 \mathrm{M}$} & \multicolumn{3}{|c|}{$\left[\mathrm{RO}^{-}\right]_{0}=0.13 \mathrm{M}$} & \multicolumn{2}{|c|}{$\left[\mathrm{RO}^{-}\right]_{0}=0.20 \mathrm{M}$} \\
\hline & expt & $\operatorname{sim}$ & expt & expt & $\operatorname{sim}$ & expt & $\operatorname{sim}$ \\
\hline polymer yield (mol \%) & 42.0 & 47.7 & 88.0 & 88.0 & 86.9 & 80.0 & 77.0 \\
\hline $\mathrm{P}_{1}$ yield $(\mathrm{mol} \%)$ & 3.5 & 2.3 & 12.0 & 12.0 & 13.1 & 20.0 & 23.0 \\
\hline residual premonomer yield ( $\mathrm{mol} \%)$ & 54.5 & 50.0 & $\approx 0$ & $\approx 0$ & 0 & $\approx 0$ & 0 \\
\hline mass averaged molar mass $(\mathrm{kg} / \mathrm{mol})$ & 236 & $241^{b}$ & 249 & 238 & $263^{b}$ & 244 & $226^{b}$ \\
\hline initiator defect $(\mathrm{mol} \%)$ & - & $0.13^{c}$ & $<0.10^{a}$ & $<0.10^{a}$ & $0.11^{c}$ & - & $0.14^{c}$ \\
\hline recombination defect ( $\mathrm{mol} \%)$ & - & 0 & $<0.10^{a}$ & $<0.10^{a}$ & 0 & - & 0 \\
\hline
\end{tabular}

${ }^{a}{ }^{13} \mathrm{C}$ NMR detection limit. ${ }^{b}$ The reported simulated molar masses were obtained by multiplying the molar mass of a precursor PPV unit (264 g/mol) and the mass averaged chain length of the simulated chain length distributions (CLDs). ${ }^{c}$ The reported simulated structural defect content is obtained from the ratio of the number of defects and the total number of propagation, initiation and recombination events. ${ }^{d}$ Reaction conditions: $308 \mathrm{~K}$, $[\mathrm{HML}]_{0}=$ $0.1 \mathrm{M}$, and $\left[\mathrm{RO}^{-}\right]_{0}=0.05,0.13$, and $0.20 \mathrm{M}$. 
Errede and Gregorian. ${ }^{69}$ Based on Errede and Gregorian's activation energy of $E_{\mathrm{a}}=36.4 \mathrm{~kJ} \mathrm{~mol}^{-1}$ for the propagation step, Beach ${ }^{86}$ calculated a termolecular initiation rate coefficient $k_{\text {ini,3 }}=7 \mathrm{M}^{-2} \mathrm{~s}^{-1}$ for the CVD process. However, when the polymerization occurs in solution, the initiation reaction is bimolecular. Hence, the value for the initiation rate coefficient reported by Beach was corrected with the value for the propagation coefficient at $308 \mathrm{~K}$ (see below) to yield a crude estimate for the value of the bimolecular initiation rate coefficient: $k_{\text {ini }}=5 \times 10^{-3} \mathrm{M}^{-1} \mathrm{~s}^{-1}$. The value for the rate coefficient for the initiation reaction was further tuned based on the available experimental data to yield $k_{\text {ini }}=3 \times 10^{-3} \mathrm{M}^{-1} \mathrm{~s}^{-1}$, i.e., close to the value based on the data reported by Beach.

For the propagation rate coefficient at $308 \mathrm{~K}$, Szwarc $^{68}$ extrapolated the data reported by Errede and Gregorian ${ }^{69}$ and obtained $A=2 \times 10^{9} \mathrm{M}^{-1} \mathrm{~s}^{-1}$ and $E_{\mathrm{a}}=36.4 \mathrm{~kJ} \mathrm{~mol}^{-1}$, yielding $k_{\mathrm{p}}=1.34 \times 10^{3} \mathrm{M}^{-1} \mathrm{~s}^{-1}$ at $308 \mathrm{~K}$. It was reported ${ }^{65}$ by Errede and Szwarc that the propagation rate coefficient of a polystyryl radical should be much smaller than the propagation rate coefficient of a poly $p$-xylyl radical. The value at $308 \mathrm{~K}$ for the propagation coefficient for styrene is about $2 \mathrm{M}^{-1} \mathrm{~s}^{-1}$, much smaller than $1.34 \times$ $10^{3} \mathrm{M}^{-1} \mathrm{~s}^{-1}$. The rate coefficients for initiation and propagation were taken as indicated above: $k_{\text {ini }}=3 \times 10^{-3} \mathrm{M}^{-1} \mathrm{~s}^{-1}$ and $k_{\mathrm{p}}=$ $1.34 \times 10^{3} \mathrm{M}^{-1} \mathrm{~s}^{-1}$. Table 3 summarizes the rate coefficients used in this work. Note that the rate coefficients for the monomer formation $\left(k_{\mathrm{E} 2}\right.$ and $\left.k_{\mathrm{NA}}\right)$ are determined at $298 \mathrm{~K}$ while the polymerization kinetics $\left(k_{\mathrm{p}}\right.$ and $\left.k_{\text {ini }}\right)$ are determined at $308 \mathrm{~K}$. The temperature dependence of the acid-base and nucleophilic addition reaction is not expected to be large over a temperature interval of $10 \mathrm{~K}$.

Table 2 shows, for three polymerization conditions, the simulated polymer, ether byproduct and premonomer yield, simulated average molar mass and simulated structural defect content at a polymerization time $t=3600 \mathrm{~s}$ using the rate coefficients from Table 3 . It can be seen from these data that the simulated polymer yield displays a maximum value as a function of the base concentration. The simulated average molar masses follow the trend of the yields and reach a maximum value for an intermediate base concentration $\left[\mathrm{RO}^{-}\right]_{0}=0.13 \mathrm{M}$, in close agreement with the trends observed experimentally. The corresponding simulated mass chain length distributions are given in the Supporting Information, section 4. Although the simulated structural defect contents are somewhat above the ${ }^{13} \mathrm{C} N M R$ detection limit, they remain in the same (low) order of magnitude in all three reaction conditions in accordance with the trend observed experimentally. Also, using the kinetic parameters in Table 3, the suppression of the polymerization at the UV-vis conditions (vide supra) could be simulated: the simulated polymer yields in these conditions varied from $0.0031 \mathrm{~mol} \%$ to $0.1189 \mathrm{~mol} \%$ depending on the initial base concentration. Clearly, the kinetic Monte Carlo model is able to capture the experimentally observed trends quite well.

Evaluation of the Importance of $\alpha, \omega$-Macro-Diradical Recombination. As mentioned above, in the sulfinyl route, $\alpha, \omega$ macro-diradical recombination is not expected to have an important contribution to chain growth. However, the recombination of $\alpha, \omega$-macro-diradicals is often suggested, but was never incorporated in a kinetic model. Therefore, recombination of $\alpha, \omega$ macro-diradicals has been implemented in the kinetic Monte Carlo model to evaluate its possible influence on the precursor polymer properties. Kinetic Monte Carlo simulations, with and without recombination, are compared with simulations performed using the PREDICI software. ${ }^{78,79}$ The polymerization
Table 4. Simulated Yields and Polymer Properties at $t=3600 \mathrm{~s}$ for the Reaction Scheme in Figure 4 and a Reaction Scheme with Recombination of $\alpha, \omega$-Macrodiradicals ${ }^{a}$

\begin{tabular}{lcc}
\multicolumn{1}{c}{$\left[\mathrm{RO}^{-}\right]_{0}$} & $0.13 \mathrm{M}$ \\
Recombination rate coefficient $\left(\mathrm{M}^{-1} \mathrm{~s}^{-1}\right)$ & 0 & 5 \\
Polymer yield $(\mathrm{mol} \%)$ & 86.9 & 86.9 \\
$\mathrm{P}_{1}$ yield $(\mathrm{mol} \%)$ & 13.1 & 13.1 \\
Residual premonomer yield $(\mathrm{mol} \%)$ & 0 & 0 \\
Mass averaged molar mass $(\mathrm{kg} / \mathrm{mol})$ & 263 & 1082 \\
Initiator defect (mol \%) & 0.11 & 0.11 \\
Recombination defect $(\mathrm{mol} \%)$ & 0 & $0.07^{b}$ \\
${ }^{a}$ Reaction conditions: $308 \mathrm{~K},[\mathrm{HML}]_{0}=0.1 \mathrm{M}$, and $\left[\mathrm{RO}^{-}\right]_{0}=0.13 \mathrm{M}$. \\
${ }^{b}$ The reported simulated initiator defect content is obtained as \\
$\left(n_{\text {ini }}\right) /\left(n_{\text {ini }}+n_{p}+n_{r c}\right) \times 100 \%$ in which $\mathrm{n}_{\text {ini }} \mathrm{n}_{\mathrm{p}}$ and $\mathrm{n}_{\mathrm{rc}}$ are the number of \\
initiation, propagation and recombination events, respectively. The simulated \\
recombination defect content is obtained as $\left(n_{r c}\right) /\left(n_{i n i}+n_{p}+n_{r c}\right) \times$ \\
$100 \%$.
\end{tabular}

conditions used in both simulations are $[\mathrm{HML}]_{0}=0.1 \mathrm{M},\left[\mathrm{RO}^{-}\right]_{0}=$ $0.13 \mathrm{M}$ at $308 \mathrm{~K}$ (see Table 2). Recombination of $\alpha, \omega$-macrodiradicals is absent in the first simulation; in the second simulation, this recombination reaction is added using an arbitrary value for the rate coefficient $\left(k_{\mathrm{rc}}=5 \mathrm{M}^{-1} \mathrm{~s}^{-1}\right)$ and the effect on the polymer yield and properties is interpreted. Table 4 compares the results for both simulations.

Considering recombination results in an increase of the mass averaged molar mass by a factor 5 without affecting the yields. This implies that recombination becomes important after the monomer has been consumed and agrees with the findings of Errede and Szwarc ${ }^{65}$ that dead polymer cannot be produced by recombination of the growing diradicals because this merely doubles the molar mass of the growing species. Table 4 also indicates that the defect content due to recombination remains below the detection limit of ${ }^{13} \mathrm{C}$ NMR. On average, each $\alpha, \omega$ macro-diradical has recombined twice at $t=3600 \mathrm{~s}$; since the ratio of recombination defects $(0.07)$ to initiation defects ( 0.11$)$ is about 0.66 , the average chain contains 2 recombination defects and 3 initiator defects. This implies that recombination events could contribute to polymer growth while the resulting structural defects remain unnoticed in NMR characterization of ${ }^{13} \mathrm{C}$ labeled precursor PPV polymers. However, a clear influence of recombination can be seen in the simulated chain length distributions (CLDs).

Figure 9 shows the simulated CLDs with and without recombination at $t=60,600$, and $3600 \mathrm{~s}\left([\mathrm{HML}]_{0}=0.1 \mathrm{M}\right.$ and $\left[\mathrm{RO}^{-}\right]_{0}=$ $0.13 \mathrm{M}$ ) together with the results obtained from the PREDICI software. $^{78,79}$

Clearly, kinetic Monte Carlo and PREDICI yield identical results. From the mass CLD at $t=60 \mathrm{~s}$, when most of the monomer is consumed, it can be seen that a second peak emerges in the CLD indicating that a small number of recombination events have occurred. At $t=600 \mathrm{~s}$, more recombination events have occurred: the second peak is more pronounced and the emergence of a third peak (shoulder) at high chain lengths can be observed. At $t=3600 \mathrm{~s}$, chain lengths up to 4000 repeating units (higher than $10^{6} \mathrm{~g} / \mathrm{mol}$ p-quinodimethane) are formed. Even for the relatively low value of the recombination rate coefficient, the maximum change lengths produced, within the Monte Carlo sample size, are excessively large (up to chain lengths of 32.000 monomer units), while the experimentally observed range of 


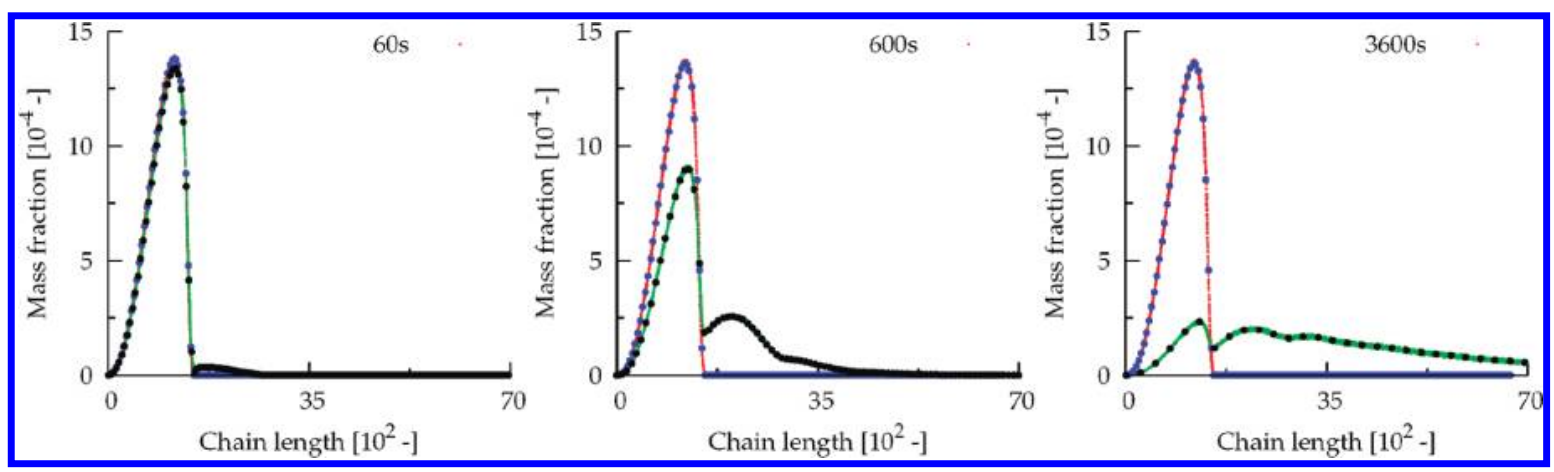

Figure 9. Simulated chain length distributions as a function of recombination rate coefficient and polymerization time. Reaction conditions: $308 \mathrm{~K}$, $[\mathrm{HML}]_{0}=0.1 \mathrm{M},\left[\mathrm{RO}^{-}\right]_{0}=0.13 \mathrm{M}$. Red line: $k_{\mathrm{rc}}=0 \mathrm{M}^{-1} \mathrm{~s}^{-1}$. Green line: $k_{\mathrm{rc}}=5 \mathrm{M}^{-1} \mathrm{~s}^{-1}$. Blue symbols: PREDICI with $k_{\mathrm{rc}}=0 \mathrm{M}^{-1} \mathrm{~s}^{-1}$. Black symbols: PREDICI with $k_{\mathrm{rc}}=5 \mathrm{M}^{-1} \mathrm{~s}^{-1}$.

molar masses is $236-249 \mathrm{~kg} / \mathrm{mol}$ (see Table 2). This again indicates again that intermolecular recombination can be safely neglected in the sulfinyl route.

For the same polymerization conditions, Adriaensens et al. ${ }^{50}$ reported a size exclusion chromatography (SEC) elugram obtained at the end of the polymerization process. The reported SEC elugram is monomodal and shows fronting, akin to the simulated CLDs in the absence of recombination. SEC elugrams showing a second peak have not been reported in any precursor route for PPV synthesis in a protic solvent. The only exception was reported by Vanderzande, ${ }^{61}$ who found a bimodal distribution in the cosolvent tetrahydrofuran $/ \mathrm{sBuOH}$. A polymeric and an oligomeric fraction was found, suggesting an anionic mechanism. ${ }^{48,55}$ In aprotic solvents, in the sulfinyl route, often oligomeric fractions are found to be the result of an anionic propagation mechanism coexisting with the radical branch which produces much longer chains. However, in protic solvents such as $\mathrm{sBuOH}$, this is unusual. Moreover, the additional peak in the simulated bimodal CLD is a high molar mass peak, which does not represent the typical oligomeric fraction originating from an anionic mechanism. The simulation data clearly indicate that recombination is negligible during the synthesis of the precursor PPV. One reason for the absence of intermolecular recombination in the sulfinyl route could be steric hindrance of the recombining $\mathrm{CHP}$ groups. For the cyclization, which will be discussed in the next paragraph, the same steric hindrance of the recombining $\mathrm{CHP}$ groups could prevent the formation of a [2.2] paracyclophane. So far, the formation of [2.2] paracyclophanes has not yet been reported in the sulfinyl route, confirming the point made above.

It can thus be concluded that, for the sulfinyl route, chain growth by recombination of $\alpha, \omega$-macro-diradicals is limited and cannot be detected in ${ }^{13} \mathrm{C}$ NMR spectra of labeled PPV polymers, nor in polymerization yields. Kinetic modeling indicates that the effect is strongly pronounced on the mass averaged molar masses and the related mass CLDs. Even if recombination would occur at low rates $\left(k_{\mathrm{rc}}=5 \mathrm{M}^{-1} \mathrm{~s}^{-1}\right)$, a second or third peak should be clearly visible in SEC elugrams.

Evaluation of the Importance of Cyclization of $\alpha, \omega$-Diradical Oligomers. Termination in the sulfinyl route may occur by cyclization of $\alpha, \omega$-diradicals similar to the Gilch ${ }^{65}$ route. In this route, the isolated cyclic products are limited to very small chain lengths and [2.2]-paracyclophane-type cyclic products have been identified as the main side products. It was suggested by Errede ${ }^{65,69}$ that cyclization becomes unlikely at higher chain lengths, especially at the typically diluted conditions of the
Table 5. Simulated Polymerization Outcome for the Reaction Scheme in Figure 4 and a Reaction Scheme Including Intramolecular Cyclization of Oligomeric $(i=2,3,4) \alpha, \omega$ Diradicals $^{a}$

\begin{tabular}{llc} 
& \multicolumn{2}{c}{$\left[\mathrm{RO}^{-}\right]_{0}=0.13 \mathrm{M}$} \\
\cline { 2 - 3 } cyclization rate coefficient $\left(\mathrm{s}^{-1}\right)$ & 0 & 10 \\
polymer yield (mol \%) & 86.9 & 84.6 \\
$\mathrm{P}_{1}$ yield (mol \%) & 13.1 & 15.2 \\
residual premonomer yield (mol \%) & 0 & 0 \\
cyclic product yield (mol \%) & 0 & 0.2 \\
mass averaged molar mass (kg/mol) & 263 & 767 \\
initiator defect (mol \%) & 0.11 & 0.09 \\
${ }^{a}$ Reaction conditions: $308 \mathrm{~K},[\mathrm{HML}]_{0}=$ & $0.1 \mathrm{M}$, and $\left[\mathrm{RO}^{-}\right]_{0}=0.13 \mathrm{M}$. \\
\hline
\end{tabular}

precursor routes. Errede ${ }^{69}$ observed that termination is second order in the total radical concentration, suggesting that the main termination mechanism cannot be cyclization for every chain length and that cyclization mainly occurred for oligomeric (chain lengths $i=2,3$, 4) diradicals.

According to Schwalm et al., ${ }^{36}$ the formation of cyclic oligomers may go unnoticed as they do not precipitate with the polymer and, therefore, cannot be detected by ${ }^{13} \mathrm{C} \mathrm{NMR}^{35}$ of precipitated polymer samples produced via the sulfinyl route. $^{35}$ To evaluate the effect of intramolecular cyclization of oligomeric (chain lengths $i=2,3,4) \alpha, \omega$-diradicals on the yields and polymer properties, simulations with and without cyclization are compared. The same polymerization conditions as above are used, i.e., $[\mathrm{HML}]_{0}=0.1 \mathrm{M}$ and $\left[\mathrm{RO}^{-}\right]_{0}=$ $0.13 \mathrm{M}$. Since literature data on cyclization in the sulfinyl route are not available, the value for the rate coefficient for cyclization is set at an arbitrary value of $10 \mathrm{~s}^{-1}$ resulting in a yield of cyclic products of $0.2 \mathrm{~mol} \%$ (see Table 5 ).

For $p$-xylylene polymerization, Errede ${ }^{69}$ reports cyclic oligomer yields in the order of $1 \mathrm{~mol} \%$ indicating that in the absence of a polarizer, $\mathrm{P}$, the tendency for intramolecular recombination of the unsubstituted $\alpha, \omega$-diradicals ( $i=2,3$, and 4$)$ is higher than that of their sulfinyl counterparts due to the absence of steric hindrance exerted by the CHP-group. As mentioned, the yield of cyclic products is distributed with respect to the chain length $i, i$ ranging from 2 to 4 . The CLD of the cyclic products is given in Table 6; the yield of the cyclic products in this CLD is $0.2 \mathrm{~mol} \%$ 
Table 6. Chain Length Distribution for the Cyclic Products Formed via Cyclization $^{a}$

\begin{tabular}{cccc} 
chain length & 2 & 3 & 4 \\
number fraction & 0.40 & 0.33 & 0.27 \\
mass fraction & 0.28 & 0.34 & 0.38 \\
${ }^{a}$ Reaction conditions: & $308 \mathrm{~K},[\mathrm{HML}]_{0}=0.1 \mathrm{M}$, and $\left[\mathrm{RO}^{-}\right]_{0}=0.13 \mathrm{M}$. \\
\hline
\end{tabular}

and hence very small compared to the CLD of the $\alpha, \omega$-macroradicals which represents $84.6 \mathrm{~mol} \%$. The total mass CLD is essentially the mass CLD of the $\alpha, \omega$-macrobiradicals.

Considering cyclization of small oligomeric $\alpha, \omega$-diradicals results in a large increase in mass averaged molar mass of the macroradicals because the cyclization of the oligomeric $\alpha, \omega$ diradicals leads to a lower total radical concentration. Schwalm et al. observed ${ }^{36,37}$ up to $30 \%$ yields of [2.2]-paracyclophane (the internally recombined dimer diradical) in the Gilch route while the produced polymers exhibited mass averaged molar masses up to $10^{6} \mathrm{~g} / \mathrm{mol}$. In our view, it is highly likely that these high chain lengths not only result from chain growth by recombination of $\alpha, \omega$-macro-diradicals, as suggested by Schwalm et al., ${ }^{37}$ but can, at least partly, also be attributed to the large cyclization rates and the concomitant increase in chain length.

In the presence of cyclization, the fraction of initiation defects at the end of the process is $0.1 \mathrm{~mol} \%$, which is lower than in case cyclizations are absent. This can be explained by the fact that the initiation defects of the cyclic oligomers are not taken into account for the calculation of the initiation defects in Table 5, as explained in the Supporting Information, section 1. For the calculation of polymer properties and structural defects, the high molar mass fraction, i.e., the $\alpha, \omega$-macro-diradicals, is considered.

Our simulations indicate that even very low yields of cyclic oligomers would lead to an important increase of the chain length. In contrast to the Gilch route, the isolation of cyclic products has not been reported for the sulfinyl route, most likely due to their very low yields and increased sterical hindrance of the sulfinyl groups $\left(P=\mathrm{S}(\mathrm{O}) \mathrm{C}_{8}\right)$ compared to the Gilch $(P=\mathrm{Cl})$ and $p$-xylylene polymerizations $(P=\mathrm{H})$. Apparently, the cyclization of small oligomeric $\alpha, \omega$-diradicals can be safely neglected for the sulfinyl route.

Effect of Reaction Conditions on Monomer and Polymer Formation. After ensuring that termination reactions can be neglected, the effect of the reaction conditions on the PPV process can be investigated over a broad range of concentrations. Section 5 in the Supporting Information illustrates this and allows to conclude that the final polymer properties and yields are only influenced by the ratio $\left[\mathrm{RO}^{-}\right]_{0} /[\mathrm{HML}]_{0}$. This can be understood by the bimolecular nature of all concerned reactions and, hence, the independence of the relative reaction rates on the absolute values of the concentrations. It must be stressed that there is no dilution effect on the final yields and properties because unimolecular reactions are absent in the model. The direct consequence of the above observation is that a single independent variable, i.e., $\left[\mathrm{RO}^{-}\right]_{0} /[\mathrm{HML}]_{0}$, can be used to visualize the results.

Focusing on the regime of interest, i.e., where high polymer yields are obtained, the reactant concentrations are varied over a narrow range to see how chain length and structural defects of the precursor polymer can be influenced. The simulation results are displayed in Figure 10 which shows the final yields and properties as a function of the initial reactant ratio $\left[\mathrm{RO}^{-}\right]_{0} /[\mathrm{HML}]_{0}$ for two values of $[\mathrm{HML}]_{0}$
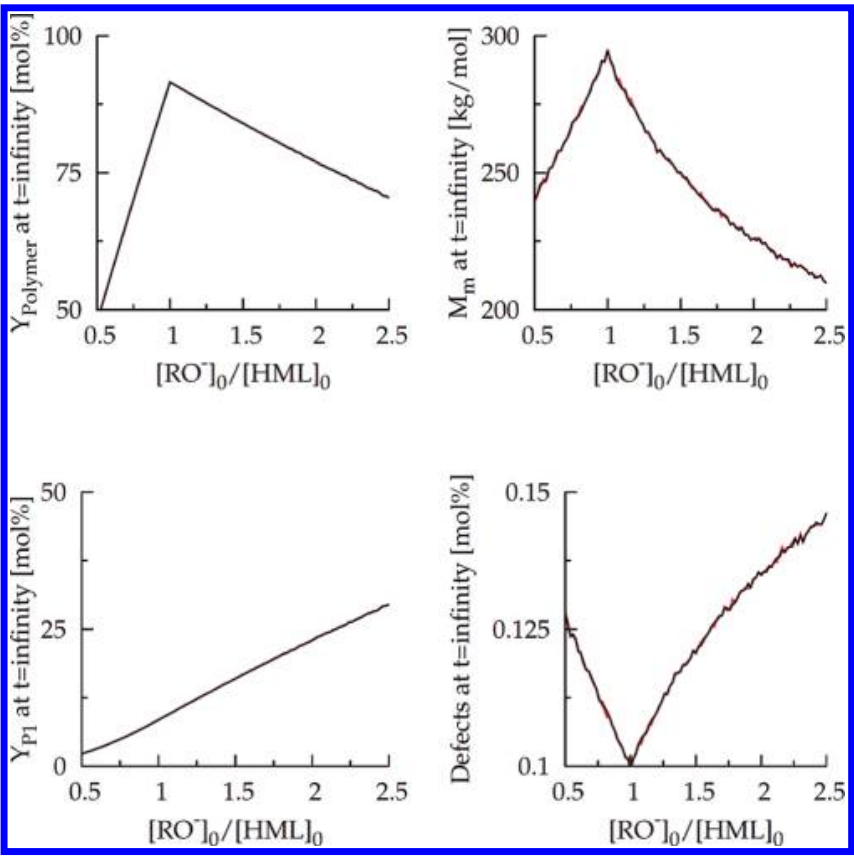

Figure 10. Influence of the ratio of initial base to premonomer concentration on the simulated final yields of substitution product $\mathrm{P}_{1}$ and polymer, the mass averaged molar mass and the structural defect content. Reaction conditions: $[\mathrm{HML}]_{0}=10^{-1} \mathrm{M}$ (red line), $10^{-2} \mathrm{M}$ (black line), and $308 \mathrm{~K}$.

(0.1 and $0.01 \mathrm{M})$. Again, it is clear that the final yields and properties depend only on $\left[\mathrm{RO}^{-}\right]_{0} /[\mathrm{HML}]_{0}$. The absolute values of the reactant concentrations only influence the rate at which the reaction system approaches the final values. As noted before, the polymer yield for $\left[\mathrm{RO}^{-}\right]_{0} /[\mathrm{HML}]_{0}=1.3$ is higher than for $\left[\mathrm{RO}^{-}\right]_{0} /[\mathrm{HML}]_{0}=0.5$ and $\left[\mathrm{RO}^{-}\right]_{0} /[\mathrm{HML}]_{0}=$ 2.0. However, an even higher polymer yield can be achieved for $\left[\mathrm{RO}^{-}\right]_{0} /[\mathrm{HML}]_{0}$ equal to unity. The occurrence of this maximum can be understood from the behavior of the substitution product yield $Y_{\mathrm{P} 1}$ as a function of $\left[\mathrm{RO}^{-}\right]_{0} /[\mathrm{HML}]_{0}$ : as the base excess increases, more and more substitution product is formed at the cost of polymer formation, as their sum equals $100 \mathrm{~mol} \%$ yield. However, for $\left[\mathrm{RO}^{-}\right]_{0} /[\mathrm{HML}]_{0}$ lower than unity, not enough base is present to convert all of the premonomer to monomer, lowering both polymer and byproduct yield and increasing the amount of unreacted premonomer. Hence, neither too low nor too high base concentrations are suitable for obtaining high polymer yields.

Figure 10 also shows the corresponding mass averaged molar mass as a function of $\left[\mathrm{RO}^{-}\right]_{0} /[\mathrm{HML}]_{0}$ : it can be seen that the mass averaged molar mass follows the trend of the polymer yield, for the same reasons as mentioned before. The actual value of the mass averaged molar mass varies between $200 \mathrm{~kg} / \mathrm{mol}$ and $300 \mathrm{~kg} / \mathrm{mol}$, depending on the reaction condition.

As shown above, termination can be neglected in the sulfinyl route and, hence, every precursor polymer chain contains only 1 structural defect due to initiation. This means that the lowest initiation defect fraction will always correspond to the highest average chain lengths (compare the upper and lower right-hand graphs in Figure 10). Figure 10 also illustrates that the defect content can be changed by no less than $50 \%$ (from $0.1 \mathrm{~mol} \%$ to $0.15 \mathrm{~mol} \%$ depending on the reaction condition). 
In addition, the mass averaged molar mass (see Figure 10) yields an estimate of the potential conjugated chain length of the precursor polymer chains. Neglecting the Gaussian nature of propagation steps (at both ends of the initiator defect) and assuming a perfect thermal elimination of the precursor polymer, the simulated mass averaged conjugated chain length corresponds to exactly half of the mass averaged molar mass. However, it must be mentioned that experimentally measured conjugation lengths are strong functions of the measurement technique itself, and by no means they lead to a unique value of the conjugated chain length. In any case, the value of the conjugation length simulated must be considered an upper limit of the real value.

The simulation results clearly show that, for a given combination of premonomer and base with its inherent kinetics, there is a unique reaction condition which will result in the highest polymer yield and the highest chain lengths with the lowest amounts of defects. Moreover, the structural defect content and chain (and conjugation) length can be varied by as much as $50 \%$ by changing the proper choice of $\left[\mathrm{RO}^{-}\right]_{0} /[\mathrm{HML}]_{0}$.

\section{CONCLUSIONS}

A kinetic model for the base-inducted polymerization reaction of 1-(chloromethyl)-4-[(n-octylsulfinyl)methyl]benzene in $\mathrm{sBuOH}$ was developed to investigate the effect of reaction conditions on PPV polymer properties. Experiments were designed to determine values for rate coefficients for the monomer formation and ether byproduct formation. Experimental and simulated reaction conditions span a product range from $95 \%$ polymer yield to $100 \%$ ether byproduct yield. The kinetic Monte Carlo model succeeds in predicting the experimentally observed trends over a broad range of experimental conditions, such as the suppression of polymerization and the competition between the anionic formation of the ether byproduct and precursor polymer formation via a radical mechanism. The effect of intramolecular and intermolecular recombination during precursor PPV synthesis was modeled and found to be negligible upon comparison with experimental data.

It was shown that the final polymer yield and properties are only determined by the ratio $\left[\mathrm{RO}^{-}\right]_{0} /[\mathrm{HML}]_{0}$, while the absolute concentration values determine the rate at which the final yields and properties are approached. Simulations allowed determination of reaction conditions yielding targeted polymer yields and mass averaged molar masses with targeted amount of structural defects, which can serve as a guideline for precursor synthesis of conjugated polymers.

\section{ASSOCIATED CONTENT}

S Supporting Information. Section 1, kinetic Monte Carlo model; section 2, mathematical details of the Guggenheim method; section 3, linear regression for the determination of $k_{\mathrm{E} 2}$ and $k_{\mathrm{NA}}$; section 4 , mass chain length distributions; section 5 , effect of reaction conditions on monomer and polymer formation. This material is available free of charge via the Internet at http://pubs.acs.org.

\section{ACKNOWLEDGMENT}

P.V.S. acknowledges financial support from the Interuniversity Attraction Poles Programme, Belgian State, Belgian Science Policy, the Institute for the Promotion of Innovation through
Science and Technology in Flanders (IWT Vlaanderen), and the "Long Term Structural Methusalem Funding by the Flemish Government”. J.V. gratefully acknowledges the fund for Scientific Research Flanders (FWO), for granting a Ph.D. fellowship.

\section{REFERENCES}

(1) Burroughes, J.; Bradley, D.; Brown, A.; Marks, R.; Friend, R.; Holmes, A. Nature 1990, 347, 539.

(2) Friend, R.; Gymer, R.; Holmes, A.; Burroughes, J.; Marks, R.; Taliani, C.; Bradley, D.; Dos Santos, D.; Bredas, J.; Logdlund, M.; Salaneck, W. Nature 1999, 397, 121-128.

(3) Meir, H. Angew. Chem. 1992, 104, 1425-46.

(4) Hide, F.; Diaz-Garcia, M. A.; Schwartz, B. J.; Heeger, A. J. Acc. Chem. Res. 1997, 30, 430-436.

(5) McGehee, M. D.; Heeger, A. I. Adv. Mater. 2000, 12, 1655-1668.

(6) Petty, M. C., Bryce, M. R., Bloor, D., editors. Introduction to molecular electronics; Edward Arnold: London, 1995.

(7) Loutfy, R. O.; Hor, A. M.; Hsiao, C. K.; Baranyi, G.; Kazmaier, P. Pure Appl. Chem. 1988, 60, 1047-1054.

(8) Nalwa, H. S., Ed. Nonlinear optics of organic molecules and polymers; CRC: New York, 1997.

(9) Feringa, L.; Jager, W. F.; de Lange, B. Tetrahedron 1993, 49, 8267-8310.

(10) Pan, J.-Q.; Chen, Z.-K.; Xiao, Y.; Huang, W. Chin. J. Polym. Sci. 2000, 18 (6), 541-549.

(11) Sirringhaus, H.; Brown, P. J.; Friend, R. H.; Nielsen, M. M.; Bechgaard, K.; Langeveld-Voss, B. M. W.; Spiering, A. J. H.; Janssen, R. A. J.; Meijer, E. W.; Herwig, P.; de Leeuw, D. M. Nature 1999, 401, 685 .

(12) Erb, T.; Raleva, S.; Zhokhavets, U.; Gobsch, G.; Stühn, B.; Spode, M.; Ambacher, O. Thin Solid Films 2004, 450, 97.

(13) Greiner, A.; Martelock, H.; Heitz, W. Synth. Met. 1991, $41-43,881-884$.

(14) Heitz, W.; Brugging, W.; Freund, L.; Gailberger, M.; Greiner, A.; Jung, H.; Kampschulte, I.; Niesner, N.; Osan, F.; Schmidt, H. W.; Wicker, M. Makromol Chem 1988, 189, 119-127.

(15) Greiner, A.; Heitz, W. Makromol. Chem. Rapid Commun. 1988, 9, 581-588.

(16) Brenda, M.; Greiner, A.; Heitz, W. Makromol Chem 1990, 191, 1083-1100.

(17) Wayne Cooke, A.; Wagener, K. B. Macromolecules 1991, 24, 1404-1407.

(18) Wang, D.; Wei, P.; Wu, Z. Macromolecules 2000, 33, 6896-6898.

(19) Conticello, V. P.; Gin, D. L.; Grubbs, R. H. J. Am. Chem. Soc. 1992, 114, 9708-9710.

(20) Staring, E. G.; Braun, D.; Rikken, G. L. J. A.; Demandt, R. J. C. E.; Kessener, Y. A. R. R.; Bouwmans, M.; Broer, D. Synth. Met. 1994, 67, $71-75$.

(21) Chang, W.-P.; Whang, W.-T.; Lin, P.-W. Polymer 1996, 37, $1513-1518$.

(22) Diliën, H.; Vandenbergh, J.; Banishoeb, F.; Adriaensens, P.; Cleij, T. J.; Lutsen, L.; Vanderzande, D. J. M. Macromolecules 2011, 44, $711-718$.

(23) de Kok, M. M.; van Breemen, A. J. J. M.; Adriaensens, P. J.; van Dixhoorn, A.; Gelan, J. M.; Vanderzande, D. J. Acta Polym. 1998, 49, $510-513$.

(24) Gowri, R.; Padmanaban, G.; Ramakrishnan, S. Synth. Met. 1999, 101, 166-169.

(25) Chen, Z. K.; Pan, J. Q.; Lee, N. H. S.; Chua, S. J.; Huang, W. Thin Solid Films 2000, 363 (1-2), 98-101.

(26) Kesters, E.; de Kok, M. M.; Carleer, R. A. A.; Czech, J. H. P. B.; Adriaensens, P. J.; Gelan, J. M.; Vanderzande, D. J. Polymer 2002, 43, 5749-5755.

(27) Kesters, E.; Vanderzande, D.; Lutsen, L.; Penxten, H.; Carleer, R. Macromolecules 2005, 38 (4), 1141-1147. 
(28) Kesters, E.; Gillissen, S.; Motmans, F.; Lutsen, L.; Vanderzande, D. Macromolecules 2002, 35, 7902-7910.

(29) Henckens, A.; Colladet, K.; Fourier, S.; Cleij, T. J.; Lutsen, L.; Gelan, J.; Vanderzande, D. Macromolecules 2005, 38 (1), 19-26.

(30) de Kok, M. M.; Nguyen, T. P.; Molinie, P.; van Breemen, A. J. J. M.; Vanderzande, D. J.; Gelan, J. M. Synth. Met. 1999, 102 (1-3), 949-950.

(31) Henckens, A.; Duyssens, I.; Lutsen, L.; Vanderzande, D.; Cleij, T. I. Polvmer 2000, 47, 123-131.

(32) Adriaensens, P.; Roex, H.; Vanderzande, D.; Gelan, J. Polymer 2005, 46 (6), 1759-1765.

(33) Wiesecke, J.; Rehan, M. Macromol. Rapid Commun. 2007, 28, 188-193.

(34) Wiesecke, J.; Rehahn, M. Angew. Chem. 2003, 42 (5), 567.

(35) Roex, H.; Adriaensens, P.; Vanderzande, D.; Gelan, J. Macromolecules 2003, 36, 5613-5622.

(36) Schwalm, T.; Rehahn, M. Macromolecules 2007, 40, 3921-3928.

(37) Schwalm, T.; Wiesecke, J.; Immel, S.; Rehahn, M. Macromol. Rapid Commun. 2009, 30, 1295-1322.

(38) Schwalm, T.; Wiesecke, J.; Immel, S.; Rehahn, M. Macromolecules 2007, 40, 8842-8854.

(39) Schwalm, T.; Rehahn, M. Macromol. Rapid Commun. 2008, 29, 207-213.

(40) Becker, H.; Spreitzer, H.; Ibrom, K.; Kreuder, W. Macromolecules 1999, 32 (15), 4925-4932.

(41) Wiesecke, J.; Rehahn, M. Macromol. Rapid Commun. 2007, 28 (1), 78-83.

(42) Gilch, H. G.; Wheelwright, W. L. J. Polym. Sci., Part A-1 1966, 4, 1337-1349.

(43) Schwalm, T.; Rehahn, M. Macromol. Rapid Commun. 2008, 29, 33-38.

(44) Vanderzande, D. J. M.; Hontis, L.; Palmaerts, A.; Van Den Bergh, D.; Wouters, J.; Lutsen, L.; Cleij, T. Proc. SPIE 2005, 5937, 59370Q-1.

(45) Louwet, F.; Vanderzande, D.; Gelan, J. Synth. Met. 1992, 52 (1), $125-130$.

(46) Hontis, L.; Lutsen, L.; Vanderzande, D.; Gelan, J. Synth. Met. 2001, 119 (1-3), 135-136.

(47) Louwet, F.; Vanderzande, D.; Gelan, J.; Mullens, J. Macromolecules 1995, 28 (4), 1330-1331.

(48) Hontis, L.; Vrindts, V.; Vanderzande, D.; Lutsen, L. Macromolecules 2003, 36, 3035-3044.

(49) Issaris, A.; Vanderzande, D.; Adriaensens, P.; Gelan, J. Macromolecules 1998, 31 (14), 4426-4431.

(50) Adriaensens, P.; Van der Borght, M.; Hontis, L.; Issaris, A.; van Breemen, A.; de Kok, M.; Vanderzande, D.; Gelan, J. Polymer 2000, 41 (19), 7003-7009.

(51) Hermosilla, L.; Catak, S.; Van Speybroeck, V.; Waroquier, M.; Vandenbergh, J.; Motmans, F.; Adriaensens, P.; Lutsen, L.; Cleij, T.; Vanderzande, D. Macromolecules 2010, 43 (18), 7424-7433.

(52) Hontis, L.; Van der Borght, M.; Vanderzande, D.; Gelan, J. Polvmer 1999, 40 (23), 6615-6617.

(53) Issaris, A.; Vanderzande, D.; Gelan, J. Polymer 1997, 38 (10), 2571-2574.

(54) Louwet, F.; Vanderzande, D.; Gelan, J. Synth. Met. 2005, 69 $(1-3), 509-510$.

(55) van Breemen, A. J. J. M.; Issaris, A. C. J.; de Kok, M. M.; Van der Borght, M. J. A. N.; Adriaensens, P. J.; Gelan, J. M. J. V.; Vanderzande, D. J. M. Macromolecules 1999, 32 (18), 5728-5735.

(56) Van der Borght, M.; Adriaensens, P.; Vanderzande, D.; Gelan, J. Polvmer 2000, 41 (8), 2743-2753.

(57) Hontis, L.; Vrindts, V.; Lutsen, L.; Vanderzande, D.; Gelan, J. Polvmer 2001, 42 (13), 5793-5796.

(58) Lutsen, L.; Adriaensens, P.; Becker, H.; van Breemen, A. J.; Vanderzande, D.; Gelan, J. Macromolecules 1999, 32 (20), 6517-6525.

(59) Vandenbergh, J.; Wouters, J.; Adriaensens, P.; Mensa, R.; Cleij, T.; Lutsen, L.; Vanderzande, D. Macromolecules 2009, 30, 1295-1322.

(60) Cho, B. R. Prog. Polvm. Sci. 2002, 27 (2), 307-355.
(61) Gillissen, S.; Lutsen, L.; Vanderzande, D.; Gelan, J. Synth. Met. 2001, $119(1-3), 137-138$.

(62) Cho, B. R.; Kim, T. H.; Son, K. H.; Kim, Y. K.; Lee, Y. K.; Jeon, S. I. Macromolecules 2000, 33 (22), 8167-8172.

(63) Wessling, R. A. I.Polvm. Sci.: Polvm. Svmp. 1985, 72, 55-66.

(64) Denton, F. R.; Lahti, P. M.; Karasz, F. E. J. Polym. Sci., Part A: Polvm. Chem. 1992, 30 (10), 2223-2231.

(65) Errede, L. A.; Szwarc, M. Q. Rev. 1958, 12 (4), 301-320.

(66) Schafer, O.; Brink-Spalink, F.; Greiner, A. Macromol. Rapid Commun. 1999, 20 (4), 190-193.

(67) Cho, B. R.; Kim, Y. K.; Han, M. S. Macromolecules 1998, 31, 2098-2016.

(68) Szwarc, M. Polvm. Eng. Sci. 1976, 16 (7), 473-479.

(69) Errede, L.; Gregorian, R.; Hoyt, J. J. Am. Chem. Soc. 1960, $82,5218-5223$.

(70) Itoh, T.; Nakanishi, E.; Okayama, M.; Kubo, M. Macromolecules 2000, 33 (2), 269-277.

(71) Son, S.; Lovinger, A. J.; Galvin, M. E. Science 1995, 269, 376-378.

(72) Son, S.; Lovinger, A. J.; Galvin, M. E. Polym. Mater. Sci. Eng. 1995, 72, 567-568.

(73) de Kok, M. M.; van Breemen, A. J. J. M.; Adriaensens, P. J.; van Dixhoorn, A.; Gelan, J. M.; Vanderzande, D. J. Acta Polym. 1998, 49, 510-513.

(74) Errede, L. A.; Hoyt, J. M. J. Am. Chem. Soc. 1960, 82 (2), $436-439$.

(75) Yin, C.; Yang, C.-Z. Synth. Met. 2001, 118, 75-79.

(76) Cho, B. R.; Han, M. S.; Suh, Y. S.; Oh, K. J.; Jeon, S. J. J. Chem. Soc., Chem. Commun. 1993, 6, 564-566.

(77) Pyun, S. Y.; Kim, W. G.; Jeong, J.-H.; Cho, B. R. Bull. Korean Chem. Soc. 2008, 29, 2453-2458.

(78) Wulkow, M. Macromol. React. Eng. 2008, 2 (6), 461-494.

(79) Wulkow, M. Macromol. Theor. Simul. 1996, 5 (3), 393-416.

(80) Bianchi, C.; Grassl, B.; Francois, B.; gron-Lartigau, C. J. Polym. Sci. Part A 2005, 43 (19), 4337-4350.

(81) Kim, T. H.; Park, S. M. Electrochim. Acta 2005, 50 (7-8), 1461-1467.

(82) Gillespie, D. T. I.Phys. Chem. 1977, 81 (25), 2340-2361.

(83) Frost, A. A.; Pearson, R. G. Kinetics and Mechanism: Wiley: Tokyo, 1961.

(84) Fleck, G. Chemical Reactions and Mechanisms: Holt, Rinehart and Winston, Inc.: New York, N.Y., 1971.

(85) Denton, F., III; Sarker, A.; Lahti, P. M.; Garay, R. O.; Karasz, F. E. I. Polvm. Sci. 1992, 30, 2233-2240.

(86) Beach, W. F. Macromolecules 1978, 11 (1), 72-76. 